\title{
A phase I study of afatinib for patients aged 75 or older with advanced non-small cell lung cancer harboring EGFR mutations
}

\author{
Hisashi Tanaka ${ }^{1}$ (1) $\cdot$ Kageaki Taima $^{1} \cdot$ Yoshihito Tanaka ${ }^{1} \cdot$ Masamichi Itoga $^{1} \cdot$ Yoshiko Ishioka $^{1} \cdot$ Hideyuki Nakagawa $^{2}$. \\ Keisuke $\mathrm{Baba}^{3} \cdot$ Yukihiro Hasegawa $^{3} \cdot$ Shingo Takanashi $^{4} \cdot$ Sadatomo Tasaka $^{1}$
}

Received: 16 January 2018 / Accepted: 5 February 2018 / Published online: 8 February 2018

(c) The Author(s) 2018. This article is an open access publication

\begin{abstract}
This phase I trial was conducted to determine the maximum tolerated dose (MTD) and recommended dose of afatinib for phase II trial in elderly patients with advanced non-small cell lung cancer (NSCLC) harboring epidermal growth factor receptor (EGFR) mutations. The study used a standard $3+3$ dose escalation design. Patients aged 75 years or older with advanced NSCLC harboring EGFR mutations were enrolled. The doses of afatinib, which were given once daily, were planned as follows: level 1, $20 \mathrm{mg} /$ day; level 2, $30 \mathrm{mg} /$ day; level 3, $40 \mathrm{mg} /$ day. Dose-limiting toxicity (DLT) was defined as grade 4 hematologic, persistent grade $>2$ diarrhea for $>2$ days despite concomitant medications or grade 3 non-hematologic toxicity. DLT was evaluated during day 1-28. Fifteen patients were enrolled. Patient characteristics were: male/female 3/12; median age 79 (range 75-87); PS 0/1, 2/13. Six patients have been treated at levels 1 and 3, and three patients at level 2. At level 1, one of six patients experienced grade 3 rush, grade 3 anorexia, and grade 3 infection as DLTs. At level 2, none of three patients experienced a DLT. At level 3, two patients developed grade 3 diarrhea, one of whom also experienced grade 3 anorexia. Most frequent adverse events of any grade were diarrhea, paronychia, rush, and nausea. Most patients at level 2 and 3 required dose reduction in 3 months. MTD was defined as $40 \mathrm{mg} /$ day, and recommended dose for phase II study in elderly patients was $30 \mathrm{mg} /$ day.
\end{abstract}

Keywords Non-small cell lung cancer $\cdot$ Epidermal growth factor receptor mutation $\cdot$ Afatinib $\cdot$ Elderly patients

\section{Abbreviations}

MTD Maximum tolerated dose

NSCLC Non-small cell lung cancer

EGFR Epidermal growth factor receptor
ECOG Eastern Cooperative Oncology Group

PS Performance status

DLT Dose-limiting toxicity

AE Adverse event
Hisashi Tanaka

xyghx335@gmail.com

Kageaki Taima

taima0305@hotmail.com

Yoshihito Tanaka

lapin2105@gmail.com

Masamichi Itoga

gacchi88@hotmail.com

Yoshiko Ishioka

ishiokayoshiko@gmail.com

Hideyuki Nakagawa

nakahide@hirosaki-hosp.jp

Keisuke Baba

babaeculus@gmail.com

Yukihiro Hasegawa

yukihiro_hasegawa@med.pref.aomori.jp
Shingo Takanashi

t-shingo@hirosaki-u.ac.jp

Sadatomo Tasaka

tasaka@hirosaki-u.ac.jp

1 Department of Respiratory Medicine, Hirosaki University Graduate School of Medicine, 5, Zaifu-cho, Hirosaki 036-8562, Japan

2 Department of Respiratory Medicine, Hirosaki National Hospital, 1, Tomino, Hirosaki, Japan

3 Department of Respiratory Medicine, Aomori Prefectural Central Hospital, 1-1-2, Higashitukurimichi, Aomori, Japan

4 Health Administration Center, Hirosaki University, 5, Zaifu-cho, Hirosaki, Japan 


$\begin{array}{ll}\text { TKI } & \text { Tyrosine kinase inhibitor } \\ \text { HER 2 } & \text { Human epidermal growth factor receptor } 2 \\ \text { PFS } & \text { Progression-free survival } \\ \text { DLT } & \text { Dose-limiting toxicity } \\ \text { RD } & \text { Recommend dose } \\ \text { UMIN } & \text { University Hospital Medical Information } \\ & \text { Network } \\ \text { RECIST } & \text { Response evaluation criteria in solid tumors } \\ \text { CTCAE } & \text { Common terminology criteria for adverse } \\ & \text { events } \\ \text { ORR } & \text { Overall response rate } \\ \text { PR } & \text { Partial response } \\ \text { CR } & \text { Complete response } \\ \text { SD } & \text { Stable disease } \\ \text { OS } & \text { Overall survival }\end{array}$

\section{Introduction}

Lung cancer is the leading cause of cancer-related death in the world, with non-small cell lung cancer (NSCLC) accounting for $85 \%$ [1]. Along with an aging society, elderly patients diagnosed with lung cancer also have been increasing. The rate of the patients aged 80 years or older is $14 \%$, and those aged patients 70 years or older was $47 \%$ of all lung cancers [2]. Therefore, it has become increasingly important to establish more effective and safe treatment for elderly patients. Patients with epidermal growth factor receptor (EGFR) mutations are recommended to receive molecular target therapy such as gefitinib, erlotinib and afatinib [3-7]. More recently, osimertinib which is the third generation EGFR-tyrosine kinase inhibitor (TKI), is used for the patients with T790 M-positive NSCLC [8]. Afatinib is a novel, potent, small-molecule ErbB family blocker that covalently binds and irreversibly blocks signaling through activated EGFR, human epidermal growth factor receptor 2 (HER2), and ErbB4 receptors [9, 10]. In two pivotal phase III studies, afatinib showed better progression-free survival (PFS) than standard platinum-based chemotherapy [7, 11]. In addition, LUX-Lung 7 study revealed that afatinib might offer improved PFS compared with gefitinib and that the number of patients discontinuing treatment due to adverse events (AEs) was similar in each group [12]. Diarrhea and skin rush were the commonest AEs for afatinib. Moreover, grade $>3$ AEs were more frequent for afatinib $(31 \%)$ than gefitinib (19.5\%) [12]. Thus, the choice of TKI should be based on the balance between efficacy and safety because the toxicity profiles are different among TKIs. Regarding as the definition of elderly patients, we have searched through the published literature. The elderly are considered as $>75$ years in Europe, whereas $>65$ in USA [13, 14]. In the Japanese lung cancer guideline, elderly patients are defined as $>75$ years of age and gefitinib is recommended for the treatment of mutation-positive NSCLC in such patients. Two prospective phase II studies of gefitinib that recruited patients with NSCLC harboring EGFR mutation who were ineligible for cytotoxic chemotherapy owing to their PS or age were reported $[15,16]$. In addition, a prospective randomized phase II study that compared erlotinib to vinorelbine for the patients aged 70 years or older was reported from Taiwan [17]. However, there has been no prospective study that examines the efficacy and safety of afatinib in elderly patients yet. Therefore, we conducted a phase I study to determine the maximum tolerated dose (MTD) and the recommended dose (RD) of afatinib for phase II trial in elderly patients aged 75 or older with NSCLC harboring EGFR mutations.

\section{Materials and methods}

\section{Study design}

This clinical trial was an open-label, multicenter trial utilizing a standard $3+3$ dose escalation protocol involving 3 institutions in Aomori prefecture, Japan. Patients received afatinib once daily with following doses: level $1,20 \mathrm{mg} /$ day; level 2, $30 \mathrm{mg}$ /day; level 3, $40 \mathrm{mg} /$ day. Level 0 is an option for the patient who requires dose reduction due to the toxicities in level 1. AEs were evaluated by Common Terminology Criteria for Adverse Events (CTCAE). Dose-limiting toxicity (DLT) was defined as grade $>3$ non-hematologic toxicity; persistent grade $>2$ diarrhea for $>2$ days, despite concomitant medications; grade $>4$ hematologic toxicity; febrile neutropenia; any grade interstitial lung disease. DLTs were evaluated during first 28 days to determine MTD. The MTD was defined as the highest dose at which the incidence of DLTs was less than or equal to 33.3\%. The RD of afatinib for phase II study was defined as one level lower than MTD. Changes in the dose and the number of enrolled patients in the next dosage group were determined by the toxicity. In this protocol, if a DLT was not observed in any of the first three patients, the dose was escalated to the next level. If a DLT was occurred in one of three patients, three additional patients were recruited at the same dose. If a DLT occurred in only one of six patients, dose escalation was permitted. If DLTs were observed in two of six or more patients, dose escalation was not permitted. This level was defined as the MTD. If a DLT occurred in only one of six or fewer patients in level 3, we were not able to define the MTD, and the RD was regarded as $40 \mathrm{mg} /$ day. Treatment was discontinued when the patients had disease progression, unacceptable toxicity was observed, or the patients refused treatment. This study was performed in accordance with the principles of the Declaration of Helsinki and Good Clinical Practice guidelines. This study was approved by the institutional review 
boards of Hirosaki University, Hirosaki National Hospital, and Aomori Prefectural Central Hospital. Patients decided participation in this trial after detailed explanation; written informed consent was obtained from all patients before the entry. This study was registered with the University Hospital Medical Information Network (UMIN). Clinical trial number UMIN000016441.

\section{Eligibility criteria}

Eligible patients were as follows: $\geqq 75$ years, histologically or cytologically confirmed NSCLC, EGFR mutations. The patients had measurable disease as defined by the Response Evaluation Criteria in Solid Tumors (RECIST) (version 1.1), an Eastern Cooperative Oncology Group (ECOG) performance status (PS) $0-1$. Patients also had adequate organ function; neutrophil count $\geqq 1500 / \mathrm{mm}^{3}$, hemoglobin $\geqq 9.0 \mathrm{~g} / \mathrm{dL}$, and platelet count $\geqq 100,000 / \mathrm{mm}^{3}$, aspartate transaminase and alanine transaminase levels $\leqq 100 \mathrm{IU} / \mathrm{L}$, creatinine $\leqq 1.5 \mathrm{mg} / \mathrm{dl}$ and creatinine clearance $\geqq 40$, total bilirubin concentration $\leqq 1.5 \mathrm{mg} / \mathrm{dl}$, and $\mathrm{PaO} 2 \geqq 60$ Torr or $\mathrm{SpO} 2 \geqq 95 \%$. The life expectancy more than 12 weeks was required. Patients who had undergone thoracic radiation therapy were required to finish their last treatment at least 12 weeks prior to the enrollment in the protocol. The patients were required to finish their prior chemotherapy at least 4 weeks before the enrollment. Patients with symptomatic central nervous system metastasis, uncontrolled pleural effusion requiring drainage treatment, the use of corticosteroid, hypersensitivity to afatinib or the use of immunosuppressive drugs, or concomitant disease such as active peptic ulcer, heart disease, interstitial pneumonia or pulmonary fibrosis, mental disorder, cerebrovascular disease, infection, and diabetes mellitus were excluded.

\section{Evaluation and statistical analysis}

The primary endpoints were the MTD and the RD of afatinib for phase II trial in elderly patients with advanced NSCLC harboring EGFR mutations. The overall response rate (ORR) and the PFS were secondary endpoints. The PFS was estimated using the Kaplan-Meier method. The PFS has been defined as the time from the date of treatment initiation to the date of disease progression, death, or the last contact. If neither event is observed, it is considered to be censored with the latest observation date. If the date on which disease progression is confirmed has exceeded 8 weeks after the last examination, it shall be censored with the previous examination date. If post-treatment is started, it is considered to be censored with the date of initiation. If the event is unknown in the case of transfer or non-arrival, it will be censored with the final date when the patient survival was confirmed. Statistical analyses were performed using JMP
10 (SAS Institute, Cary, NC, USA). Tumor responses were assessed using chest radiography and computed tomography scan at every 8 weeks until disease progression. Unidirectional measurements were adopted on the basis of the RECIST, version 1.1.

\section{Results}

\section{Patient characteristics}

From February 2015 to September 2016, a total of 15 patients were enrolled from three participating institutions in Aomori, Japan. Table 1 shows the characteristics of the 15 eligible patients. Six patients were included in the afatinib $20 \mathrm{mg} /$ day cohort, three patients were in the $30 \mathrm{mg} /$ day cohort and six patients were in the $40 \mathrm{mg} /$ day cohort. Six patients were included in each of the $20 \mathrm{mg} /$ day and the $40 \mathrm{mg} /$ day cohort because one of the first three patients experienced a DLT, requiring the enrollment of additional three patients. Three male (20\%) patients and 12 female $(80 \%)$ patients, with a median age of 79 years (range, 75-87 years), were included. The histology was adenocarcinoma in all patients. Two patients had stage IIIB, 11 had stage IV, and two had recurrent disease. The EGFR mutation status was as follows: exon $19 \mathrm{del} /$ exon $21 \mathrm{~L} 858 \mathrm{R} /$ exon

Table 1 Patient characteristics $(N=15)$

\begin{tabular}{ll}
\hline Gender & \\
Male/female $(n)$ & $3 / 12$ \\
Age (years), median (range) $79(75-87)$ & \\
ECOG PS $[n(\%)]$ & $13(86.7)$ \\
$0-1$ & $2(13.3)$ \\
2 & \\
Clinical stage $[n(\%)]$ & $2(13.3)$ \\
IIIB & $11(73.4)$ \\
IV & $2(13.3)$ \\
Recurrence & \\
Histological type $[n(\%)]$ & $15(100)$ \\
Adenocarcinoma & \\
Smoking history $[n(\%)]$ & $12(80)$ \\
Never smoker & $3(20)$ \\
Light smoker & \\
EGFR mutation $[n(\%)]$ & $3(20)$ \\
Exon 19 del & $11(73.4)$ \\
Exon 21 L858R & $1(6.6)$ \\
Exon 18 G719 & \\
No. of prior treatment regimen $[n(\%)]$ & $13(86.7)$ \\
0 & $2(13.3)$ \\
$1-2$ & \\
\hline
\end{tabular}

$E C O G$ Eastern Cooperative Oncology Group; $P S$ performance status 
18 G719X in 3/11/1, respectively. Two patients (13.3\%) received prior chemotherapy (one patient received gefitinib as the first-line treatment and erlotinib as the second-line treatment, and the other received platinum-based chemotherapy), and 13 patients (86.7\%) were chemo-naïve.

\section{MTD and toxicity analysis}

The DLTs observed during day 1-28 at each dose level are summarized in Table 2. Six patients were enrolled in the $20 \mathrm{mg} /$ day cohort, three patients in the $30 \mathrm{mg} /$ day cohort, and six patients in the $40 \mathrm{mg} /$ day cohort. One patient experienced DLTs at the $20 \mathrm{mg} /$ day cohort. Grade 3 rash, anorexia and infection were observed in a 77 -year-old

Table 2 Observed dose-limiting toxicities in treatment during day 1-28 at each dose level

\begin{tabular}{llll}
\hline Treatment level & Afatinib (mg/day) & \\
\cline { 2 - 4 } & $\begin{array}{l}\text { Level 1 } \\
20 \mathrm{mg} / \text { day } \\
n=6\end{array}$ & $\begin{array}{l}\text { Level 2 } \\
30 \mathrm{mg} / \text { day } \\
n=3\end{array}$ & $\begin{array}{l}\text { Level 3 } \\
40 \mathrm{mg} / \text { day } \\
n=6\end{array}$ \\
\hline Patients number & 6 & 3 & 6 \\
DLT, n (\%) & 1 (16.7) & 0 & $2(33.3)$ \\
Details of DLTs & $\begin{array}{l}77 \text { years, female } \\
\text { Grade 3 rash, } \\
\text { anorexia and } \\
\text { infection }\end{array}$ & & $\begin{array}{l}75 \text { years, female } \\
\text { Grade 3 diar- } \\
\text { rhea }\end{array}$ \\
& & $\begin{array}{l}80 \text { years, female } \\
\text { Grade 3 } \\
\text { diarrhea, and } \\
\text { anorexia }\end{array}$ \\
\hline
\end{tabular}

woman. At the $30 \mathrm{mg} / \mathrm{day}$ cohort, no DLT was observed in 3 patients. At the $40 \mathrm{mg} /$ day cohort, two patients experienced DLTs. Grade 3 diarrhea was observed in a 75-year-old woman, grade 3 diarrhea and anorexia were observed in an 80 year-old woman. The frequency of DLTs was $33.3 \%$ at the $40 \mathrm{mg} /$ day cohort. We considered that the MTD was $40 \mathrm{mg} /$ day. Eight of nine patients $(88.8 \%)$ enrolled in $30 \mathrm{mg} / \mathrm{day}$ and $40 \mathrm{mg} /$ day cohorts, required dose reduction of afatinib within 3 months. The primary reasons for dose reduction included diarrhea, nausea, skinrelated AEs, and mucositis. The major toxicities in all term are given in Table 3. No grade 3 or higher hematologic toxicities were observed at any level. Grade 3 non-hematologic toxicities were skin rush (20\%), anorexia (13.3\%), diarrhea (13.3\%), and nausea or vomiting (6.6\%). Most of low-grade non-hematologic toxicities were nausea, vomiting, anorexia, fatigue, paronychia, oral mucositis, and infection, which were generally mild and reversible. There were no treatment-related deaths in this phase I study.

\section{Efficacy}

The response to afatinib in the intent-to-treat population is given in Table 4. Eleven patients attained a partial response (PR), but no patients attained a complete response (CR). The ORR was $73.3 \%$, and three patients (20.1\%) had stable disease (SD). The median followup time at analysis (August 2017) was 568 days. Eight patients (53.3\%) had PD, the median PFS was 22 months (95\% CI, 13.1—not reached) (Fig. 1).

$D L T$ dose-limiting toxicities

Table 3 Toxicity in patients treated with afatinib $(n=15)$

\begin{tabular}{|c|c|c|c|c|c|c|c|c|}
\hline \multirow{3}{*}{$\begin{array}{l}\text { Afatinib } \\
\text { Grade (CTCAE) ver } 4.0\end{array}$} & \multirow{2}{*}{\multicolumn{2}{|c|}{$\begin{array}{l}20 \mathrm{mg} \\
n=6\end{array}$}} & \multirow{2}{*}{\multicolumn{2}{|c|}{$\begin{array}{l}30 \mathrm{mg} \\
n=3\end{array}$}} & \multirow{2}{*}{\multicolumn{2}{|c|}{$\begin{array}{l}40 \mathrm{mg} \\
n=6\end{array}$}} & \multirow{2}{*}{\multicolumn{2}{|c|}{$\begin{array}{l}\text { All dose } \\
n=15\end{array}$}} \\
\hline & & & & & & & & \\
\hline & $1-2$ & 3 & $1-2$ & 3 & $1-2$ & 3 & All grade $(\%)$ & $3(\%)$ \\
\hline Neutropenia & 1 & 0 & 0 & 0 & 0 & 0 & $1(6.6)$ & 0 \\
\hline Anemia & 3 & 0 & 3 & 0 & 1 & 0 & 7 (46.6) & 0 \\
\hline Thrombocytopenia & 0 & 0 & 0 & 0 & 0 & 0 & 0 & 0 \\
\hline Nausea, vomiting & 3 & 0 & 1 & 0 & 2 & 1 & 7 (46.6) & $1(6.6)$ \\
\hline Anorexia & 1 & 1 & 2 & 0 & 2 & 1 & $7(46.6)$ & $2(13.3)$ \\
\hline Fatigue & 2 & 0 & 2 & 0 & 2 & 0 & $6(40)$ & 0 \\
\hline Diarrhea & 6 & 0 & 3 & 0 & 4 & 2 & $15(100)$ & $2(13.3)$ \\
\hline Skin rush & 2 & 1 & 3 & 0 & 4 & 2 & $12(80)$ & $3(20)$ \\
\hline Paronychia & 0 & 0 & 3 & 0 & 3 & 0 & $6(40)$ & 0 \\
\hline Oral mucositis & 0 & 0 & 2 & 0 & 3 & 0 & $5(33.3)$ & 0 \\
\hline Increased AST & 2 & 0 & 0 & 0 & 1 & 0 & $3(20)$ & 0 \\
\hline Infection & 1 & 1 & 0 & 0 & 1 & 0 & $3(20)$ & 0 \\
\hline Increased Creatinine & 0 & 0 & 0 & 0 & 1 & 0 & $1(6.6)$ & 0 \\
\hline
\end{tabular}

AST Aspartate aminotransferase; CTCAE common terminology criteria for adverse events 
Table 4 Response to afatinib in the intent-to-treat population

\begin{tabular}{lll}
\hline Response & Number of patients & $\%$ \\
\hline Complete response & 0 & 0 \\
Partial response & 11 & 73.3 \\
Stable disease & 3 & 20.1 \\
Progressive disease & 0 & 0 \\
Not evaluable & 1 & 6.6 \\
Response rate & $73.3 \%$ & \\
\hline
\end{tabular}

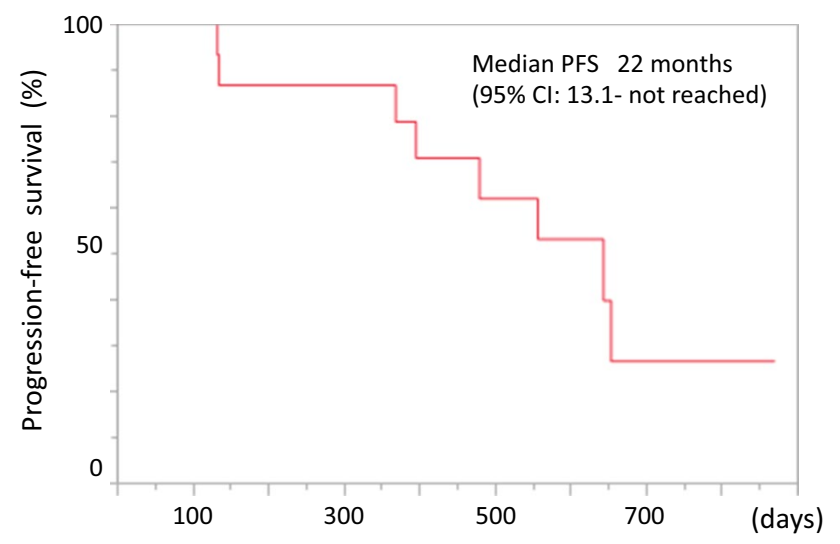

Fig. 1 Kaplan-Meier analysis of progression-free survival for all 15 treated patients

\section{Discussion}

This is the first phase I study demonstrating that afatinib has manageable safety profiles for patients aged 75 or older with advanced NSCLC harboring EGFR mutations. The MTD was defined as $40 \mathrm{mg} /$ day, and the RD for phase II study in elderly patients was $30 \mathrm{mg} /$ day. The MTDdefining DLTs were rash, anorexia, infection, and diarrhea, which recovered by the temporal discontinuation or dose reduction. In a previous phase I study of afatinib in patients with advanced solid tumors, median age of the patients was 56 years, and the RD for phase II study was reported as $50 \mathrm{mg} /$ day [18]. Similarly, a phase I study in younger patients with previously treated NSCLC showed that $50 \mathrm{mg} /$ day of afatinib was well tolerated [19]. Thus, the starting dose of afatinib was $40 \mathrm{mg} /$ day in a phase III NSCLC trial [20]. The most frequent drug-related AEs were diarrhea, dry skin, stomatitis, rash, paronychia and anorexia, and an increased frequency and severity of drug-related AEs were observed accompanied with higher doses of afatinib [18, 19]. In LUX-lung 7, Paz-Ares and colleagues reported that there was no difference of overall survival (OS) among patient subgroups, and similar median OS was seen at cutoffs of $60,65,70$, and 75 years
[21]. In that study, however, the number of patients aged 75 or older were small, and moreover, AEs in this age group was not reported. The efficacy and safety of afatinib in such patients has not been clear yet.

Previous reports suggested that dosing of small-molecule TKIs according to body surface area (BSA) might be meaningful. In a phase I trial of sunitinib, low BSA was associated with higher incidence of severe AEs and DLTs [22]. In the first-generation EGFR-TKIs (gefitinib and erlotinib), dose reduction was not required according to BSA [23]. Recently, Wada and colleagues reported that lower BSA $\left(<1.50 \mathrm{~m}^{2}\right)$ was significantly associated with higher frequency of diarrhea grade $>2$ in patients treated with afatinib [24]. In our study, median BSA of recruited patients was $1.35 \mathrm{~m}^{2}$ (range 0.93-1.59), comparable with the subject of a previous study [24]. We observed higher frequency of diarrhea than in a previous report, which might be due to older age of the study subjects. In our study, mean BSA of the patients who experienced DLTs was $1.23 \mathrm{~m}^{2}$, although the sample size was too small to discuss the relationship between low BSA and DLTs in afatinib treatment.

The efficacy was not the primary end point of this study, but the ORR in our study was $73.3 \%$, similar to the results of the previously reported clinical trials [7, 20, 21].

In conclusion, the MTD was defined as $40 \mathrm{mg} / \mathrm{day}$, and the RD for phase II study in elderly patients aged 75 or older was $30 \mathrm{mg} /$ day. Afatinib showed a manageable safety profile and efficacy comparable with those described in the previous studies, although they remain to be evaluated in a phase II study. Now a phase II clinical trial that evaluates the efficacy of afatinib in elderly patients aged 75 or older is ongoing in Japan (UMIN000017877).

Acknowledgements The authors are grateful to the patients and their family and the investigators, nurses, and staff members who participated in this study. The authors also thank assistant professor Michiko Shimada from Hirosaki University Hospital for English editing and formatting this manuscript for submission and Takeshi Morimoto from Hirosaki National Hospital for management of clinical information of registered patients in his institution.

Funding This research have been sourced from Hirosaki University

Authors' contributions All the authors contributed equally to this work. Conceptualization and design by HT. Data collection by all authors. Data analysis and interpretation done by HT and ST. Manuscript written by HT. Critical review and revisions of manuscript done by all the authors. Finally, all authors have agreed with the content and approve of the manuscript for submission.

\section{Compliance with ethical standards}

Conflict of interest All the authors declare that they have no conflict interest. 
Ethics approval All procedures performed in studies involving human participants were in accordance with the ethical standards of the institutional and/or national research committee and with the 1964 Helsinki declaration and its later amendments or comparable ethical standards. The study protocol was approved by the institutional review boards of all participating institutions. This study was registered with the University Hospital Medical Information Network (UMIN), Number UMIN000011696.

Informed consent Informed consent was obtained from all individual participants included in the study.

Open Access This article is distributed under the terms of the Creative Commons Attribution 4.0 International License (http://creativeco mmons.org/licenses/by/4.0/), which permits unrestricted use, distribution, and reproduction in any medium, provided you give appropriate credit to the original author(s) and the source, provide a link to the Creative Commons license, and indicate if changes were made.

\section{References}

1. Siegel R, Naishadham D, Jemal A. Cancer statistics 2012. CA Cancer J Clin. 2012;62:10-29.

2. Owonikoko TK, Ragin CC, Belani CP, et al. Lung cancer in elderly patients: an analysis of the surveillance, epidemiology, and end results database. J Clin Oncol. 2007;25:5570-7.

3. Maemondo M, Inoue A, Kobayashi K, et al. Gefitinib or chemotherapy for non-small-cell lung cancer with mutated EGFR. N Engl J Med. 2010;362:2380-8.

4. Mitsudomi T, Morita S, Yatabe Y, et al. Gefitinib versus cisplatin plus docetaxel in patients with non-small-cell lung cancer harbouring mutations of the epidermal growth factor receptor (WJTOG3405): an open label, randomised phase 3 trial. Lancet Oncol. 2010;11:121-8.

5. Zhou C, $\mathrm{Wu} \mathrm{YL}$, Chen G, et al. Erlotinib versus chemotherapy as frst-line treatment for patients with advanced EGFR mutationpositive non-small-cell lung cancer (OPTIMAL, CTONG-0802): a multicentre, open-label, randomised, phase 3 study. Lancet Oncol. 2011;12:735-42.

6. Rosell R, Carcereny E, Gervais R, et al. Erlotinib versus standard chemotherapy as first-line treatment for European patients with advanced EGFR mutation-positive non-small-cell lung cancer (EURTAC): a multicentre, open-label, randomised phase 3 trial. Lancet Oncol. 2012;13:239-46.

7. $\mathrm{Wu} \mathrm{YL}, \mathrm{Zhou} \mathrm{C}, \mathrm{Hu} \mathrm{CP}$, et al. Afatinib versus cisplatin plus gemcitabine for first-line treatment of Asian patients with advanced non-small-cell lung cancer harbouring EGFR mutations (LUXLung 6): an open-label, randomised phase 3 trial. Lancet Oncol. 2014;15:213-22.

8. Mok TS, Wu Y-L, Ahn M-J, et al. Osimertinib or platinum-pemetrexed in EGFR T790 M-Positive Lung Cancer. N Engl J Med. 2017;376:629-40.

9. Hynes NE, Lane HA. ERBB receptors and cancer: the complexity of targeted inhibitors. Nat Rev Cancer. 2005;5:341-54.
10. Li D, Ambrogio L, Shimamura T, et al. BIBW2992, an irreversible EGFR/HER2 inhibitor highly effective in preclinical lung cancer models. Oncogene. 2008;27:4702.

11. Yang JC, Wu YL, Schuler M, et al. Afatinib versus cisplatinbased chemotherapy for EGFR mutation-positive lung adenocarcinoma (LUX-Lung 3 and LUX-Lung 6): analysis of overall survival data from two randomised, phase 3 trials. Lancet Oncol. 2015;16:141-51.

12. Paz-Ares L, Tan EH, O'Byrne K, et al. Afatinib versus gefitinib in patients with EGFR mutation-positive advanced non-small-cell lung cancer: overall survival data from the phase IIb LUX-Lung 7 trial. Ann Oncol. 2017;28:270-7.

13. Saint-Jean O, LeGuen J. Geriatric intervention in oncology for elderly patients. Cancer Radiother. 2015;19:377-81.

14. Hohenforst-Schmidt W, Zarogoulidis P, Steinheimer M, et al. Tyrosine kinase inhibitors for the elderly. J Cancer. 2016;7:687-93.

15. Inoue A, Suzuki T, Fukuhara T, et al. Prospective phase II study of gefitinib for chemotherapy-naive patients with advanced nonsmall-cell lung cancer with epidermal growth factor receptor gene mutations. J Clin Oncol. 2006;24:3340-6.

16. Maemondo M, Minegishi Y, Inoue A, et al. First-line gefitinib in patients aged 75 or older with advanced non-small cell lung cancer harboring epidermal growth factor receptor mutations: NEJ 003 study. J Thorac Oncol. 2012;7:1417-22.

17. Chen YM, Tsai CM, Fan WC, et al. Phase II randomized trial of erlotinib or vinorelbine in chemonaive, advanced, non-small cell lung cancer patients aged 70 years or older. J Thorac Oncol. 2012;7:412-8.

18. Yap TA, Vidal L, Adam J, et al. Phase I trial of the irreversible EGFR and HER2 kinase inhibitor BIBW 2992 in patients with advanced solid tumors. J Clin Oncol. 2010;28:3965-72.

19. Murakami H, Tamura T, Takahashi T, et al. Phase I study of continuous afatinib (BIBW 2992) in patients with advanced nonsmall cell lung cancer after prior chemotherapy/erlotinib/gefitinib (LUX-Lung 4). Cancer Chemother Pharmacol. 2012;69:891-9.

20. Sequist LV, Yang JC, Yamamoto N, et al. Phase III study of afatinib or cisplatin plus pemetrexed in patients with metastatic lung adenocarcinoma with EGFR mutations. J Clin Oncol. 2013;31:3327-34

21. Paz-Ares L, Tan EH, O'Byrne K, et al. Afatinib versus gefitinib in patients with EGFR mutation-positive advanced non-small-cell lung cancer: overall survival data from the phase IIb LUX-Lung 7 trial. Ann Oncol. 2017;28:270-7.

22. Huillard O, Mir O, Peyromaure M, et al. Sarcopenia and body mass index predict sunitinib-induced early dose-limiting toxicities in renal cancer patients. Br J Cancer. 2013;108:1034-41.

23. Sato S, Kurishima K, Miyazaki K, et al. Efficacy of tyrosine kinase inhibitors in non-small-cell lung cancer patients undergoing dose reduction and those with a low body surface area. Mol Clin Oncol. 2014;2:604-8.

24. Wada Y, Koyama S, Kuraishi H, et al. Clinical analysis of patients treated with afatinib for advanced non-small cell lung cancer: A Nagano Lung Cancer Research Group observational study. Respir Invest. 2016;54:462-7. 